\title{
Rapid identification of Aspergillus fumigatus within the section Fumigati
}

\author{
Rita Serrano ${ }^{1,2}$, Leonor Gusmão1, António Amorim ${ }^{1,2}$ and Ricardo Araujo ${ }^{1 *}$
}

\begin{abstract}
Background: New fungal species that are morphologically similar to Aspergillus fumigatus were recently described and included in section Fumigati. Misidentification of such fungal species, particularly of the human pathogens, Aspergillus lentulus, Neosartorya fischeri, Neosartorya hiratsukae, Neosartorya pseudofischeri and Neosartorya udagawae, has been increasingly reported by numerous clinical labs. Nevertheless, A. fumigatus still accounts for more than $90 \%$ of all invasive aspergillosis cases. The purpose of the present study was to develop a rapid method for the molecular identification of $A$. fumigatus to distinguish it from other species within the section Fumigati.

Results: A multiplex PCR was developed using prior information based on $\beta$-tubulin ( $\beta$ tub) and rodlet A (rodA) partial gene sequences. PCR amplification of $\beta$ tub and rodA fragments resulted in a distinctive electrophoretic pattern in A. fumigatus and $N$. udagawae. The polymorphisms found in the smallest amplified sequence of $\beta$ tub (153 bp) and rodA (103 bp) genes were then compared among and within species of this taxonomic section. $\beta$ tub was able to differentiate among 13 individual species and two groups of species that included the pathogenic fungus A. lentulus. A more limited number of sequences were available for rodA; nevertheless, we were able to distinguish Aspergillus viridinutans, N. hiratsukae and N. udagawae.

Conclusions: The assay described in the present study proved to be specific and highly reproducible, representing a fast and economic way of targeting molecular identification of the relevant mould, A. fumigatus, in clinical laboratories.

Keywords: Aspergillus azole resistance, electrophoretic profile, invasive aspergillosis, molecular identification, mould, multiplex PCR, rodlet $A$, $\beta$-tubulin
\end{abstract}

\section{Background}

Aspergillosis is the most common invasive mould disease worldwide. Recently, molecular techniques have been applied to fungal diagnosis and to the identification of species, and new fungal species that are morphologically similar to A. fumigatus have been described, authenticated and included in section Fumigati [1-3]. Therefore, this section now includes a few anamorphous Aspergillus species and teleomorphic species that are found in the genus Neosartorya [4]. The characteristics of the colonies on standard culture media are often similar to A. fumigatus, but conidia may be rather distinct. Neosartorya species produce heat-resistant ascospores [4].

\footnotetext{
* Correspondence: ricjparaujo@yahoo.com

1IPATIMUP, Institute of Molecular Pathology and Immunology of the University of Porto, Rua Dr. Roberto Frias s/n, 4200-465 Porto, Portugal Full list of author information is available at the end of the article
}

Misidentification of fungal species within the section Fumigati has been increasingly reported by clinical laboratories. Species, such as Aspergillus lentulus, Aspergillus viridinutans, Aspergillus fumigatiaffinis, Aspergillus fumisynnematus, Neosartorya pseudofischeri, Neosartorya hiratsukae and Neosartorya udagawae, are frequently reported as A. fumigatus $[1,2,5,6]$. Some of these species have been described as human pathogens, particularly $A$. lentulus, A. viridinutans, $N$. pseudofischeri and N. udagawae, and some species have been reported to be resistant in vitro to the azole antifungals itraconazole, miconazole, posaconazole, ravuconazole and/or voriconazole $[7,8]$. Therefore, molecular identification is currently recommended for the correct identification of species within the "A. fumigatus complex" group. Sequencing of genes, such as actin, calmodulin, ITS, rodlet A ( $\operatorname{rodA})$ and/or $\beta$ tubulin ( $\beta$ tub), has been used to distinguish $A$. fumigatus from related species [4,9]. Multilocus sequence typing
C Biomed Central

(C) 2011 Serrano et al; licensee BioMed Central Ltd. This is an Open Access article distributed under the terms of the Creative Commons Attribution License (http://creativecommons.org/licenses/by/2.0), which permits unrestricted use, distribution, and reproduction in any medium, provided the original work is properly cited. 
can alternatively be used for the identification of those related species, which is a strategy that also involves sequencing of several gene fragments [5]. A few other techniques, such as random amplified polymorphic DNA $[10,11]$, restriction fragment length polymorphisms [12] and a new proposed microsphere-based Luminex assay [13], may enable molecular identification of $A$. fumigatus without sequencing. However, these methodologies are quite time consuming and labour demanding and are thus impractical in most clinical labs. In addition, they can be very expensive when employed to study collections of large numbers of isolates.

Thus, a rapid, practical and cheap alternative method for the molecular identification of A. fumigatus and the distinction of the species within the section Fumigati is required. In this study, a multiplex PCR was developed using prior information based on $\beta$ tub and rodA partial gene sequences. We propose a single PCR to target the molecular recognition of the A. fumigatus fungus, avoiding the use of restriction enzymes. Additional sequencing of fragments of $\beta$ tub and $\operatorname{rod} A$ allowed the identification of several A. fumigatus related species.

\section{Results}

\section{Multiplex optimization}

The present strategy was proposed to simultaneously target $\beta$ tub and rodA gene fragments that are specific to a single species (A. fumigatus) and other gene fragments that are common to a group of species (all species of section Fumigati). A similar strategy was attempted with calmodulin sequences from species within the section Fumigati, but we could not obtain primers that were specific for A. fumigatus (data not shown). Thus, pairs of primers were selected based on the information on polymorphic and conserved regions of $\beta$ tub and rodA genes among fungal species, as shown in Table 1 (for primer design criteria see the Methods section). As primer specificity could be improved by increasing the amplification temperature, a range from $60^{\circ} \mathrm{C}$ to $72^{\circ} \mathrm{C}$ was tested with our multiplex; highly specific primers work at high temperatures (Figure 1), whereas the amplification of some regions (e.g., the rodA region of $313 \mathrm{bp}$ ) could only be observed in non-fumigatus species at $60^{\circ} \mathrm{C}$. A region of the $\beta$ tub gene of 198 bp was observed only in A. fumigatus even when low amplification temperatures were tested. The electrophoretic profile obtained for each fungal species was very clear, revealing few secondary and/or minor bands as a consequence of primer combinations in the multiplex PCR (four nonspecific bands in the case of A. fumigatus and occasionally two bands in the case of non-fumigatus species). Those secondary bands did not reduce the performance of the multiplex PCR, as shown in Figure 1.

\section{Rapid identification of Aspergillus fumigatus}

Multiplex PCR was successfully conducted in all fungal strains included in the study. The specificity of the primers at $69^{\circ} \mathrm{C}$ was confirmed by the results obtained with singleplex PCR and amplification of each gene fragment in A. fumigatus: partial sequences of 153 and $198 \mathrm{bp}$ for $\beta$ tub, and 105 and 313 bp for rodA. The electrophoretic profile with four bands (105, 153, 198 and $313 \mathrm{bp})$ was similar in all 35 tested strains of $A$. fumigatus. Non-fumigatus isolates of section Fumigati, specifically A. fumigatiaffinis, A. lentulus, A. novofumigatus, A. unilateralis, $N$. hiratsukae, and N. pseudofischeri, produced two discrete bands (105 and $153 \mathrm{bp}$ ) corresponding to the conserved region of the section Fumigati for which the primers were designed (as showed in Figure 1). Neosartorya udagawae was an exception and formed a third band (with $313 \mathrm{bp}$ ) in a location that was similar to the amplification of A. fumigatus. Amplicon sizes were confirmed using automated electrophoresis with the primers stained with 6-FAM. Therefore, the present multiplex PCR targeting $\beta$ tub and rodA gene fragments resulted in a distinct band pattern in A. fumigatus compared to the band pattern obtained for the other species of section Fumigati. In addition, a clear differentiation of $N$. udagawae was also observed. The electrophoretic profile of the Aspergillus species of other taxonomic sections was distinct from the

Table 1 Forward (F) and reverse (R) PCR primers employed for molecular identification of all Aspergillus species of section Fumigati and for Aspergillus fumigatus

\begin{tabular}{|c|c|c|c|c|}
\hline \multicolumn{4}{|c|}{ Primers $\left(5^{\prime}-3^{\prime}\right)$} & \multirow{2}{*}{$\frac{\text { Fragment length }}{153 \mathrm{bp}}$} \\
\hline Aspergillus section Fumigati & $\beta$-tubulin & $F$ & AGGCAGACCATCTCTGGTGAG & \\
\hline & & $\mathrm{R}$ & TCGGAGGAGCCATTGTAGC & \\
\hline & Rodlet A & $\mathrm{F}$ & CCAGGCTCAGCTCTCTTGCT & $105 \mathrm{bp}$ \\
\hline & & $\mathrm{R}$ & CCACCACCGATGAGGTTCTT & \\
\hline \multirow[t]{4}{*}{ A. fumigatus } & $\beta$-tubulin & $\mathrm{F}$ & TGACGGGTGATTGGGATCTC & 198 bp \\
\hline & & R & CGTCCGCTTCTTCCTTGTTI & \\
\hline & Rodlet A & $\mathrm{F}$ & ACATTGACGAGGGCATCCTT & $313 \mathrm{bp}$ \\
\hline & & $\mathrm{R}$ & ATGAGGGAACCGCTCTGATG & \\
\hline
\end{tabular}




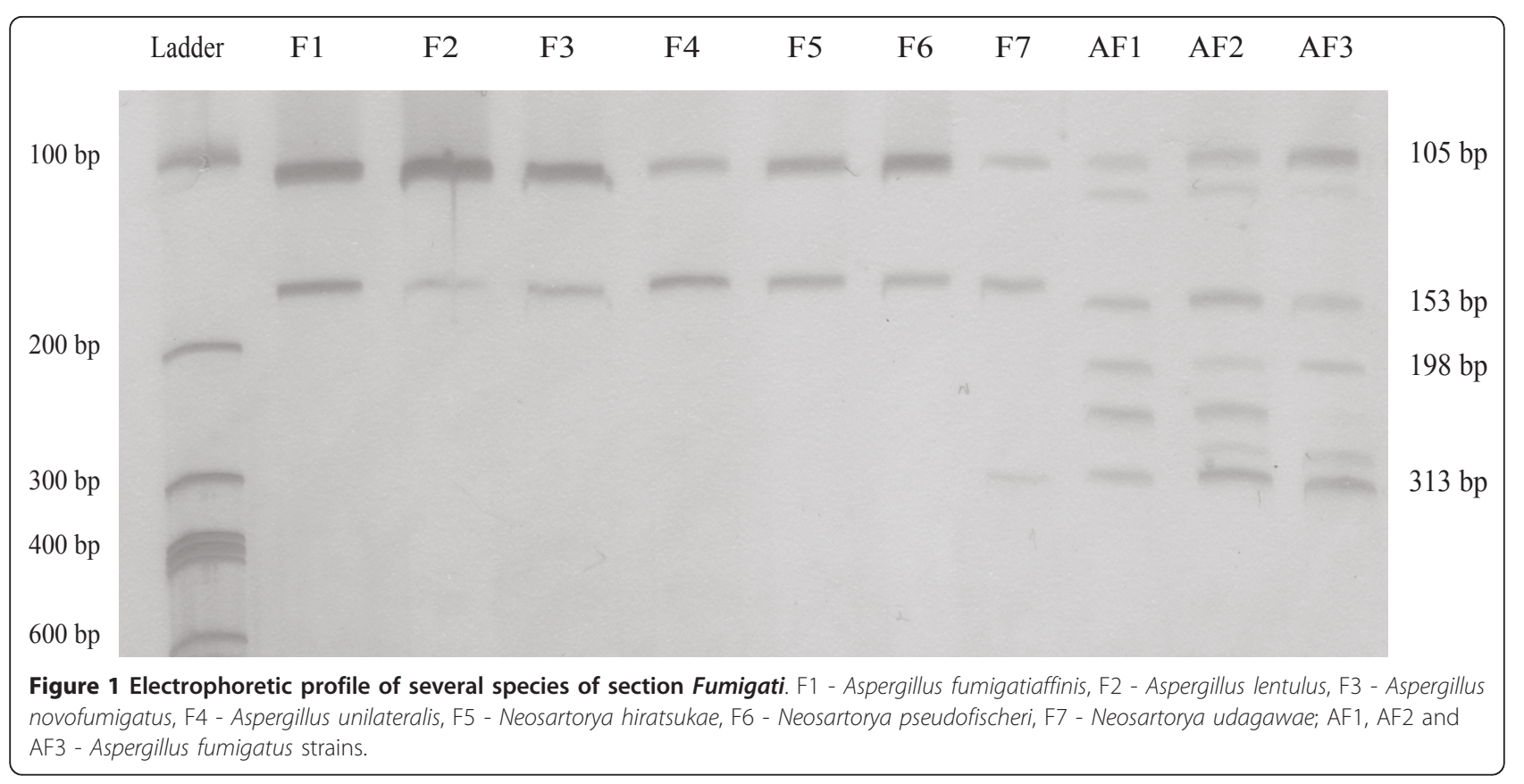

profile observed for A. fumigatus and was rarely similar to the profile obtained for species included in section Fumigati (two bands of 105 and $153 \mathrm{bp}$ ).

\section{Identification of species within the section Fumigati}

The polymorphisms found in the small gene fragments of $\beta$ tub (153 bp) and $\operatorname{rodA}(103 \mathrm{bp}$ ) were compared among and between species of section Fumigati. A group of 425 partial sequences of $\beta$ tub and rodA from fungal species of section Fumigati available at GenBank and EMBL-Bank were downloaded (annotation numbers are available as supplemental data; see additional file 1). A detailed alignment of $\beta$ tub and rodA sequences of the species included in section Fumigati is available in Figures 2 and 3. The most relevant and exclusive polymorphic sites for each species within the section Fumigati were registered. The $153 \mathrm{bp}$ region of $\beta$ tub was able to differentiate 13 fungal species of section Fumigati (A. fumigatus, A. fumigatiaffinis, A. novofumigatus,
$N$. aurata, $N$. aureola, $N$. hiratsukae, $N$. fennelliae, $N$. fischeri, N. pseudofischeri, N. spathulata, N. stramenia, $N$. tatenoi and $N$. udagawae) and two groups of species (the first with $A$. brevipes, A. duricaulis and $N$. quadricinta; and the second with $A$. fumisynnematus and $A$. lentulus). The polymorphisms that were capable of distinguishing the pathogenic moulds of section Fumigati are detailed in Table 2. A more limited number of sequences were available for $\operatorname{rodA}(105 \mathrm{bp})$ within the section Fumigati; nevertheless, this small portion of DNA allowed the distinction of A. viridinutans, N. hiratsukae and N. udagawae (Table 2). Sequencing of a rodA fragment revealed no polymorphisms in A. novofumigatus (the information for this species was not available from the NCBI or EMBL banks).

\section{Recognition of low sporulating isolates}

We employed the present molecular strategy to identify two low sporulating Aspergillus isolates that were

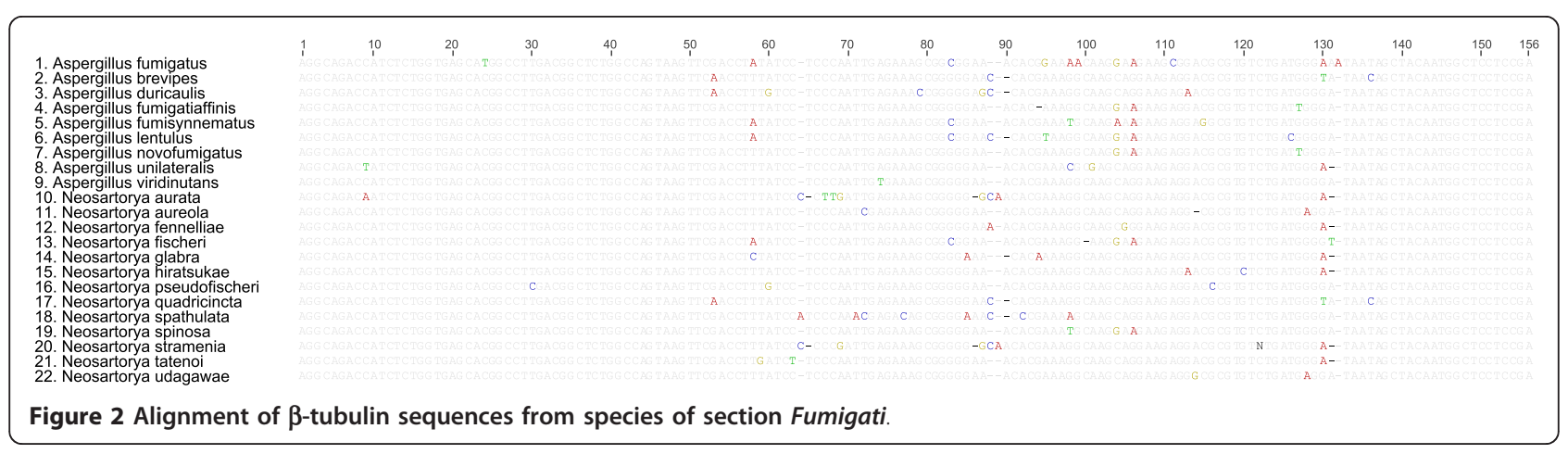




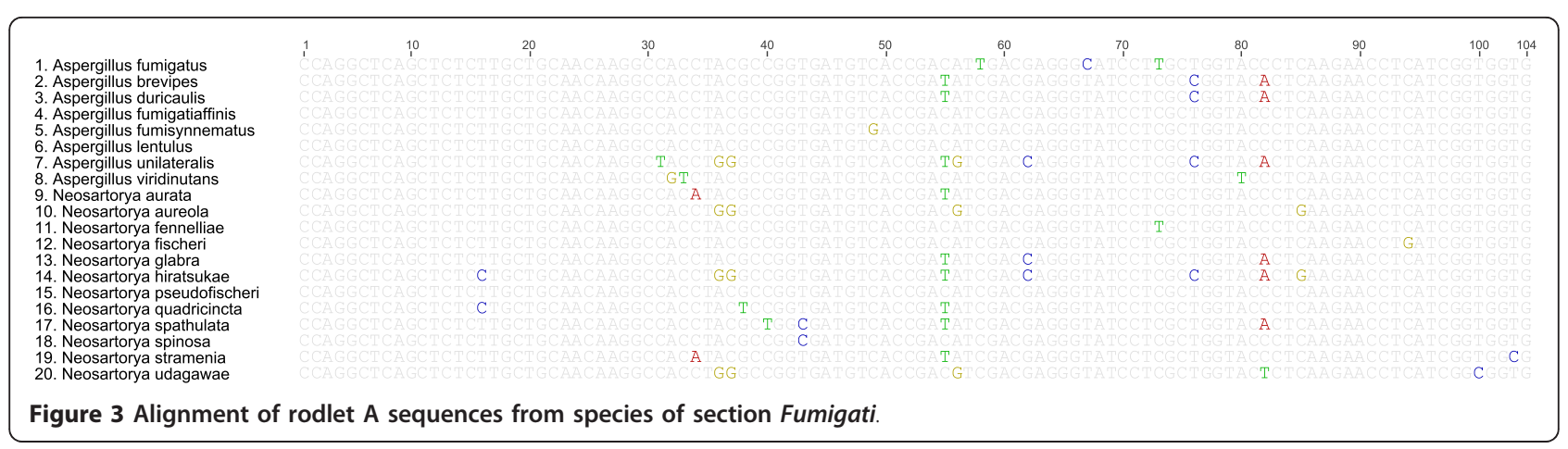

available in our collection and are both able to grow at $45^{\circ} \mathrm{C}$. The isolates showed two discrete bands of 105 and $153 \mathrm{bp}$ on the electrophoretic profile with multiplex amplification. After sequencing, those isolates were identified as A. fumigatiaffinis (deletion of a guanine in position 93).

\section{Discussion}

Recently, new fungal species have been identified within the section Fumigati, some of which have been implicated in severe cases of trabecular bone invasion and cutaneous, cerebral, liver or pulmonary aspergillosis [1,2,14-18]. These species might be primarily resistant to azole antifungals or to amphotericin $\mathrm{B}$, similar to $A$. fumigatiaffinis and A. lentulus $[7,8]$, whereas A. fumigatus is usually susceptible to the antifungals that are available for clinical treatment $[19,20]$. Few clinical cases of invasive aspergillosis have been reported in which the antifungal treatment was repeatedly modified until the correct identification of the fungal agent and the administration of the appropriate antifungal treatment $[17,18]$. Considering that $A$. fumigatus may represent a considerable part of all clinical cases of aspergillosis, molecular characterization is essential for the correct identification of species within the section Fumigati. In this study, we developed a multiplex PCR strategy that was able to differentiate A. fumigatus from all the other related species within the section Fumigati. We could not test all of the species of section Fumigati, as some of them are extremely rare. However, we believe that the present multiplex PCR can be widely used, as A. lentulus is more closely related to $A$. fumigatus than most species in section Fumigati (e.g. A. viridinutans) [4,5], and a distinct electrophoretic profile was observed with two strains of this species. It is expected that other species of section Fumigati that are genetically distant from A. fumigatus can be distinguished by employing this multiplex PCR (see additional file 2 in supplemental data). A simple electrophoresis profile after PCR amplification clearly separates two species, A. fumigatus and N. udagawae, from a second group of fungal isolates of section Fumigati. This method is furthermore amenable to automation. Compared to previously described methodologies for A. fumigatus identification within its section [10-13], the proposed method facilitates the molecular recognition of this species by employing a single multiplex PCR

Table 2 Specific nucleotide positions for identification of pathogenic species within the section Fumigati (inside parentheses the number of sequences studied for each species)

\begin{tabular}{|c|c|c|}
\hline Species & $\beta$-tubulin sequence & Rodlet $A$ sequence \\
\hline Aspergillus fumigatus & $\mathrm{T} 24^{\#}(96)$ & Polymorphism not found (47) \\
\hline Aspergillus fumigatiaffinis & DelG93 \# (6) & Polymorphism not found (3) \\
\hline Aspergillus lentulus * & T58A and C99 (48) & Polymorphism not found (39) \\
\hline Aspergillus viridinutans & Polymorphism not found (20) & A32G or C33T (2) \\
\hline Neosartorya fennelliae & InsA87 \# or A105G \# (18) & $\mathrm{NI}$ \\
\hline Neosartorya fischeri & DelC99 or A131T (5) & $\mathrm{NI}$ \\
\hline Neosartorya hiratsukae & G53 and G113A (10) & C55T or G62C or T76C or C82A (6) \\
\hline Neosartorya pseudofischeri & G116C (15) & Polymorphism not found (5) \\
\hline Neosartorya udagawae & $\mathrm{A} 114 \mathrm{G}(22)$ & A56G or C82T (16) \\
\hline
\end{tabular}

* Aspergillus fumisynnematus may also present these $\beta$-tubulin polymorphisms but very few sequences are still available.

\# Nomenclature: T24 - a thymine is present in position 24; DelG93 - deletion of the guanine in position 93 ; InsA87 - insertion of an adenine in position 87 ; A105G - replacement of an adenine by a guanine in position 105. The position numbers result from the gene alignment (Figures 2 and 3 ) and position 1 is located in the beginning of forward primer. (NI - not enought information, only one sequence was available). 
and avoiding the need for restriction enzymes and specialized equipment. This approach is cheap and simple and would be very useful in clinical labs that routinely screen and perform the molecular identification of several mould isolates. The proposed new assay proved to be specific and highly reproducible for targeting $A$. fumigatus within the section Fumigati and outside this section.

A list of fungal species related to A. fumigatus could be identified by sequencing partial regions of $\beta$ tub and rodA. A group of 14 unique species and two groups of species of section Fumigati were distinguished by point mutations in $\beta$ tub and $\operatorname{rodA}$. This work presents the first record of polymorphic sites available for the rapid identification of species within the section Fumigati following the analysis of more than $450 \beta$ tub and $\operatorname{rodA}$ sequences. This list represents a practical guide for the molecular recognition of rare fungal species, and it can certainly be expanded in the near future when more sequences of $\beta$ tub and $\operatorname{rod} A$ are available. At present, there is a limited number of sequences that are still available at GenBank and EMBL from species of section Fumigati, particularly for the rodA gene. The record of rodA sequences at GenBank has been improved by the addition of the information on $A$. novofumigatus.

\section{Conclusions}

As molecular diagnosis is being increasingly employed in clinical labs $[21,22]$ and some labs can only detect fungal DNA (culture of the fungal agent cannot be obtained), it will become increasingly important to possess molecular protocols for the identification of moulds while avoiding misidentification of fungal species. Thus, a multiplex PCR strategy is now available that can easily differentiate $A$. fumigatus and $N$. udagawae from other fumigatus-related species. In addition, the proposed methodology can be used in cases of low sporulating fungal isolates frequently detected in culture, as in the case of two isolates from our collection. Pathogenic species of section Fumigati could be identified by sequencing $\beta$ tub and rodA fragments by following the list of polymorphic sites provided in this work.

Molecular identification is at present recommended for the correct identification of species within the $A$. fumigatus complex group of species. The assay described in the present study proved to be specific and highly reproducible, representing a fast and economic way of targeting molecular identification of A. fumigatus in clinical laboratories.

\section{Methods}

\section{Fungal strains and culture conditions}

A set of 35 clinical isolates of $A$. fumigatus from the Department of Microbiology, Faculty of Medicine,
University of Porto, were used in this study; the reference strain, A. fumigatus ATCC 46645, was also included. The isolates were identified based on macroscopic and microscopic morphological characteristics, and standard mycological procedures were followed [23]. The genotype of this set of $A$. fumigatus isolates was unique, as established by a previously standardized microsatellite based multiplex PCR specially designed for this mould [24]. A second group of fungal strains of the section Fumigati was obtained from Centraalbureau voor Schimmelcultures (CBS): pathogenic moulds including Aspergillus fumigatiaffinis (CBS 117186), Aspergillus lentulus (CBS 116880 and CBS 117180), Neosartorya hiratsukae (CBS 124073), Neosartorya pseudofischeri (CBS 208.92), and Neosartorya udagawae (CBS 114217), and two non-pathogenic moulds of section Fumigati, Aspergillus novofumigatus (CBS 117519) and Aspergillus unilateralis (CBS 126.56). In addition, a third set of 12 isolates that included strains of other Aspergillus sections (Aspergillus flavus, Aspergillus niger, Aspergillus nidulans, Aspergillus terreus and Aspergillus glaucus) and two low sporulating Aspergillus species from our collection were included in this study. Single colonies of all fungal isolates were cultured on Sabouraud dextrose agar for 5 days at $30^{\circ} \mathrm{C}$. A sodiumhydroxide-based method was used to extract DNA from fungal conidia (the protocol is available at http://www. aspergillus.org.uk/indexhome.htm?secure/laboratory_protocols). Fungal DNA was suspended in $50 \mu \mathrm{l}$ of sterile water and frozen at $-20^{\circ} \mathrm{C}$.

\section{Molecular identification strategy}

A group of 425 partial sequences of $\beta$ tub and rodA from fungal species of section Fumigati available at GenBank and EMBL-Bank were downloaded (annotation numbers are available in Additional file 1, supplement Table A1). These sequences were aligned, and the most polymorphic and conserved regions on $\beta$ tub and $\operatorname{rod} A$ genes were identified. In these genomic regions, two groups of PCR primers were designed: 1) general primers for the amplification of $\beta$ tub and rodA gene fragments in species of section Fumigati, and 2) specific primers for amplification exclusively in A. fumigatus. The primers were selected ensuring that the resulted genomic fragments could be distinguished based on their size. The selected PCR primers are shown in Table 1.

\section{PCR amplification and amplicon visualization}

Multiplex PCR amplification was performed in a $5 \mu \mathrm{l}$ final volume containing $1 \mu \mathrm{L}$ of genomic DNA (1-5 ng/ $\mu \mathrm{L}$ ), $2.5 \mu \mathrm{L}$ of $2 \mathrm{x}$ Qiagen multiplex PCR master mix (Qiagen, Hilden, Germany) and $0.5 \mu \mathrm{L}$ of each primer (for a $0.2 \mu \mathrm{M}$ final concentration of each primer). After a preincubation at $95^{\circ} \mathrm{C}$ for $15 \mathrm{~min}$, the amplification was performed for a total of 35 cycles as follows: denaturation at 
$94^{\circ} \mathrm{C}$ for $30 \mathrm{~s}$, annealing at $69^{\circ} \mathrm{C}$ for $90 \mathrm{~s}$, extension at $72^{\circ}$ $\mathrm{C}$ for $1 \mathrm{~min}$, and a final extension step of $10 \mathrm{~min}$ at $72^{\circ} \mathrm{C}$. Singleplex PCRs were performed for the confirmation of primer specificity (a single PCR product was obtained and subsequently sequenced). Singleplex PCR amplifications were performed using the same conditions as for the multiplex amplification. Amplicons were visualized following electrophoresis in polyacrylamide gels with a standard DNA silver staining method [25].

Amplicon sizes were confirmed with automated electrophoresis. A volume of $0.5 \mu \mathrm{L}$ of the internal size standard GeneScan 500 LIZ (Applied Biosystems, Foster City, CA, USA) and $12 \mu \mathrm{L}$ of HiDi formamide (Applied Biosystems) were added to the PCR amplified products (6-FAM stained forward primers were used) and processed with an ABI PRISM 3100 Genetic Analyser 16-capillary electrophoresis system (Applied Biosystems).

\section{DNA sequencing conditions}

PCR-generated fragments were purified with ExoSAP-IT (USB Corporation, Cleveland, Ohio, USA), and the reactions were conducted with an ABI Big Dye terminator cycle sequencing kit (Applied Biosystems) under the following conditions: after a $95^{\circ} \mathrm{C}$ pre-incubation step of 15 min and DNA denaturation at $96^{\circ} \mathrm{C}$ for $15 \mathrm{~s}, 35 \mathrm{PCR}$ cycles were performed with primer annealing at $50^{\circ} \mathrm{C}$ for $9 \mathrm{~s}$, an extension at $60^{\circ} \mathrm{C}$ for $2 \mathrm{~min}$ and a final extension at $60^{\circ} \mathrm{C}$ for $10 \mathrm{~min}$. A volume of $8 \mu \mathrm{L}$ of $\mathrm{HiDi}$ formamide was added to the sequencing products, which were processed in an ABI PRISM 3100 Genetic Analyser 16-capillary electrophoresis system. The results were analyzed using the Sequencing 5.2 analysis software (Applied Biosystems).

\section{Data analysis}

$\beta$ tub and rodA partial sequences available in NCBI and EMBL for Aspergillus species of section Fumigati were aligned and compared employing the Geneious software v4.7 (Biomatters Ltd, Auckland, New Zealand) and BioEdit sequence alignment editor (available at http:// www.ctu.edu.vn/ dvxe/Bioinformatic/Software/BioEdit. htm). Sequencing results from this study, which included sequences from several $A$. fumigatus isolates and from ten strains of section Fumigati, were added to a final database that included all partial sequences of $\beta$ tub and rodA genes. Based on comparisons of all of the aligned sequences, polymorphic sites that were able to discriminate different fungal species were identified.

\section{Additional material}

Additional file 1: Accession numbers of DNA sequences. The list of all DNA sequences included in this study that were obtained from GenBank and EMBL-Bank.
Additional file 2: Alignment of $\beta$-tubulin and Rodlet A primers selected for amplification of Aspergillus fumigatus in other species of section Fumigati. The polymorphic positions identified in species of section Fumigati considering the region of the primers designed for $A$. fumigatus.

\section{Acknowledgements and Funding}

This work was supported by Fundação Calouste Gulbenkian grant n. 359924-S/2009 and partially resulted in the Master Thesis on Forensic Genetics of RS. RA is supported by Fundação para a Ciência e a Tecnologia (FCT) Ciência 2007 and by the European Social Fund. IPATIMUP is an Associate Laboratory of the Portuguese Ministry of Science, Technology and Higher Education and is partially supported by FCT.

\section{Author details}

${ }^{1}$ IPATIMUP, Institute of Molecular Pathology and Immunology of the University of Porto, Rua Dr. Roberto Frias s/n, 4200-465 Porto, Portugal. ${ }^{2}$ Faculty of Sciences, University of Porto, Rua do Campo Alegre s/n, 4169-007 Porto, Portugal.

\section{Authors' contributions}

RS and RA carried out the experimental studies and sequence alignment. $L G, A A$ and RA conceived the study, participated in its design and coordination and drafted the manuscript. All authors read and approved the final manuscript.

Received: 1 March 2011 Accepted: 21 April 2011

Published: 21 April 2011

\section{References}

1. Balajee SA, Gribskov J, Brandt M, Ito J, Fothergill A, Marr KA: Mistaken identity: Neosartorya pseudofischeri and its anamorph masquerading as Aspergillus fumigatus. J Clin Microbiol 2005, 43:5996-5999.

2. Balajee SA, Gribskov JL, Hanley E, Nickle D, Marr KA: Aspergillus lentulus sp. nov., a new sibling species of A. fumigatus. Eukaryot Cell 2005, 4:625-632.

3. Varga J, Vida Z, Tóth B, Debets F, Horie Y: Phylogenetic analysis of newly described Neosartorya species. Antonie Van Leeuwenhoek 2000, 77:235-239.

4. Samson RA, Hong S, Peterson SW, Frisvad JC, Varga J: Polyphasic taxonomy of Aspergillus section Fumigati and its teleomorph Neosartorya. Stud Mycol 2007, 59:147-203.

5. Balajee SA, Nickle D, Varga J, Marr KA: Molecular studies reveal frequent misidentification of Aspergillus fumigatus by morphotyping. Eukaryot Cell 2006, 5:1705-1712.

6. Hong SB, Shin HD, Hong J, Frisvad JC, Nielsen PV, Varga J, Samson RA: New taxa of Neosartorya and Aspergillus in Aspergillus section Fumigati. Antonie van Leeuwenhoek 2008, 93:87-98.

7. Alcazar-Fuoli L, Mellado E, Alastruey-Izquierdo A, Cuenca-Estrella M, Rodriguez-Tudela JL: Aspergillus section Fumigati: antifungal susceptibility patterns and sequence-based identification. Antimicrob Agents Chemother 2008, 52:1244-1251.

8. Yaguchi T, Horie Y, Tanaka R, Matsuzawa T, Ito J, Nishimura K: Molecular phylogenetics of multiple genes on Aspergillus section Fumigati isolated from clinical specimens in Japan. Jpn J Med Mycol 2007, 48:37-46.

9. Balajee SA, Houbraken J, Verweij PE, Hong SB, Yaghuchi T, Varga J, Samson RA: Aspergillus species identification in the clinical setting. Stud Mycol 2007, 59:39-46.

10. Brandt ME, Padhye AA, Mayer LW, Holloway BP: Utility of random amplified polymorphic DNA PCR and TaqMan automated detection in molecular identification of Aspergillus fumigatus. J Clin Microbiol 1998, 36:2057-2062.

11. Hong SB, Go SJ, Shin HD, Frisvad JC, Samson RA: Polyphasic taxonomy of Aspergillus fumigatus and related species. Mycologia 2005, 97:1316-1329.

12. Staab JF, Balajee SA, Marr KA: Aspergillus Section Fumigati typing by PCRrestriction fragment polymorphism. J Clin Microbiol 2009, 47:2079-2083.

13. Etienne KA, Gade L, Lockhart SR, Diekema DJ, Messer SA, Pfaller MA, Balajee SA: Screening of a large global Aspergillus fumigatus species complex collection by using a species-specific microsphere-based Luminex assay. J Clin Microbiol 2009, 47:4171-4172. 
14. Guarro J, Kallas EG, Godoy P, Karenina A, Gené J, Stchigel A, Colombo AL: Cerebral aspergillosis caused by Neosartorya hiratsukae, Brazil. Emerg Infect Dis 2002, 8:989-991.

15. Padhye AA, Godfrey JH, Chandler FW, Peterson SW: Osteomyelitis caused by Neosartorya pseudofischeri. J Clin Microbiol 1994, 32:2832-2836.

16. Sugui JA, Vinh DC, Nardone G, Shea YR, Chang YC, Zelazny AM, Marr KA, Holland SM, Kwon-Chung K: Neosartorya udagawae (Aspergillus udagawae), an emerging agent of aspergillosis: how different is it from Aspergillus fumigatus? J Clin Microbiol 2010, 48:220-228.

17. Vinh DC, Shea YR, Sugui JA, Parrilla-Castellar ER, Freeman AF, Campbell JW Pittaluga S, Jones PA, Zelazny A, Kleiner D, Kwon-Chung K, Holland SM: Invasive aspergillosis due to Neosartorya udagawae. Clin Infect Dis 2009, 49:102-111.

18. Vinh DC, Shea YR, Jones PA, Freeman AF, Zelazny A, Holland SM: Chronic invasive aspergillosis caused by Aspergillus viridinutans. Emerg Infect Dis 2009, 15:1292-1294.

19. Araujo R, Pina-Vaz C, Rodrigues AG: Susceptibility of environmental versus clinical strains of pathogenic Aspergillus. Int J Antimicrob Agents 2007, 29:108-111.

20. Araujo R, Coutinho I, Espinel-Ingroff A: Rapid method for testing the susceptibility of Aspergillus fumigatus to amphotericin B, itraconazole, voriconazole and posaconazole by assessment of oxygen consumption. J Antimicrob Chemother 2008, 62:1277-1280.

21. Cruz-Perez P, Butner MP, Stetzenbach LD: Detection and quantitation of Aspergillus fumigatus in pure culture using polymerase chain reaction. Mol Cell Probes 2001, 15:81-88.

22. Klingspor L, Loeffler J: Aspergillus PCR formidable challenges and progress. Med Mycol 2009, 47:S241-S247.

23. Larone DH: Medically important fungi: a guide to identification. 3 edition. Washington DC: American Society for Microbiology; 2005.

24. Araujo R, Pina-Vaz C, Rodrigues AG, Amorim A, Gusmão L: Simple and highly discriminatory microsatellite-based multiplex PCR for Aspergillus fumigatus strain typing. Clin Microbiol Infect 2009, 15:260-266.

25. Qu L, Li X, Wu G, Yang N: Efficient and sensitive method of DNA silver staining in polyacrylamide gels. Electrophoresis 2005, 26:99-101.

doi:10.1186/1471-2180-11-82

Cite this article as: Serrano et al:: Rapid identification of Aspergillus fumigatus within the section Fumigati. BMC Microbiology 2011 11:82.

\section{Submit your next manuscript to BioMed Central} and take full advantage of:

- Convenient online submission

- Thorough peer review

- No space constraints or color figure charges

- Immediate publication on acceptance

- Inclusion in PubMed, CAS, Scopus and Google Scholar

- Research which is freely available for redistribution

Submit your manuscript at www.biomedcentral.com/submit
Biomed Central 